\title{
CIENCIAS SOCIALES TRANSFORMA
}

SOCIAL SCIENCES TRANSFORM

\author{
Roly Auccatoma Tinco ${ }^{1 *}$ \\ rauccatoma@unah.edu.pe \\ ${ }^{1}$ Universidad Nacional Autónoma de Huanta, Ayacucho, Perú
}

Solo el hombre hace ciencia e interpreta, con pasión, la totalidad de lo real para transformarlo. Los científicos sociales cuentan con una actitud crítica y una consciencia práctica para construir una sociedad democrática inclusiva, para ello es necesario investigar y conocer los problemas sociales que aquejan a la humanidad y su entorno.

La subjetividad del hombre siempre ha sido tramada por los que dominan al mundo, aquellos urden los grandes mitos para poder subyugarlos y sujetarlos; por ello, el investigador de las ciencias sociales debe develar, con sus investigaciones, las grandes mentiras que avasallan a la humanidad.

Por tanto, en este sistema actual exclusivo, se debe procurar la construcción permanente de una nueva subjetividad democrática inclusiva, con miras a una nueva sociedad inclusiva. El hombre es trabajo y creación; el único ser que se asombra, angustia y duda; él ha creado toda la cultura. Por eso, Morín manifiesta:

Nosotros somos seres vivientes. Ninguna de las dimensiones de nuestro ser ha surgido fuera de la evolución biológica que conduce al ser humano. Somos diferentes a los demás seres vivientes, no porque nuestra cabeza esté separada de la mitad del cuerpo, sino porque esta cabeza viviente ha desarrollado nuevas formas de vida: vida de las ideas, vida del espíritu, vida de la sociedad. (citado por Juárez y Comboni, 2012, p. 47)

Asimismo, la sociedad está en constante dinamismo y transformación, así como la ciencia, tal como Sandoval cita a Bernal: "En realidad, la naturaleza de la ciencia ha cambiado tanto en el transcurso de la historia humana, que no podría establecerse una definición concreta" (2012, p. 57).

Por otro lado, nuestra sociedad vive la democracia desde inicios del siglo XXI, con participación en la vida política de la gran mayoría, aunque todavía no tenemos la cultura participativa. Necesitamos construir una sociedad con educación de calidad y formadora del espíritu humano (científica y técnica, humanística y social); aunque, en nuestra sociedad capitalista, prima el "sálvese quien pueda" es primordial el reconocimiento y respeto de la libertad del Otro. El ser humano es racional y social:

El hombre es un ser social; el individuo concreto no existe sino en la relación de asociación, que constituye su misma esencia humana. Pero si el hombre y la sociedad son términos recíprocos, no menos que sujeto y objeto, la praxis es la realidad de la vida social no menos que de la existencia del sujeto" (Mondolfo, 1969, p. 20).

La realidad social no tiene leyes y por eso no se puede determinar lo que sucederá en el futuro, al hacerlo podemos ser profetas, aunque la característica de la ciencia es la de predecir; con la duda se construyen conocimientos demostrados que se interpretan a 
través de su lenguaje propio. La universidad se conoce a través de las ciencias que produce; leer los textos producidos es leerse a sí mismo.

Es así que, el investigador científico de la universidad debe publicar para transformar la subjetividad de la juventud del bicentenario, para ejercer discernimiento cognitivo y actitud crítica.

En fin, el hombre es praxis y no es lenguaje: "La vida social es, en esencia, práctica. Todos los misterios que descarrían la teoría hacia el misticismo, encuentran su solución racional en la práctica humana y en la comprensión de esta práctica." (Marx y Engels, 1976, p. 10). Es decir, el devenir de los hombres de ciencia será interpretar para transformar el mundo que les tocó vivir, así como dice Marx "Los filósofos no han hecho más que interpretar de diversos modos el mundo, pero de lo que se trata es de transformarlo" (1976, p.11).

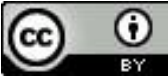

\section{REFERENCIAS BIBLIOGRÁFICAS}

Mondolfo, R. (1969). Marx y marxismo. Fondo de cultura económica. México. https://unpocodehistorianohacemal.files.wordpress.com.

Juárez, J. M. \& Comboni, S. (2012). Epistemología del pensamiento complejo. Reencuentro, núm. 65. Universidad Autónoma Metropolitana Unidad. México. https:// www.redalyc.org/pdf/340/34024824006.pdf

Marx, K., \& Engels, F. (1976). Obras escogidas. Progreso. Moscú. https://webs.ucm.es/ info/bas/es/marx-eng/oeme1.htm.

Sandoval, R. E. (2012). El Debate en torno a la Ciencia y las Ciencias Sociales. Universidad Simón Bolívar. Vol. 10, No. 2, págs. 57-61. https://dialnet.unirioja.es/servlet/ articulo? codigo $=4497235$.

CITAR COMO:
$\begin{aligned} & \text { Auccatoma Tinco, R. (2022). Ciencias sociales transforma. Puriq, 4, e259. } \\ & \text { https://doi.org/10.37073/puriq.4.1.259 }\end{aligned}$

